\title{
ARTICLE OPEN \\ Urban warming and future air-conditioning use in an Asian megacity: importance of positive feedback
}

\author{
Yuya Takane $\mathbb{D}^{1,2 *}$, Yukihiro Kikegawa $\mathbb{D}^{3}$, Masayuki Hara $\mathbb{D}^{4}$ and C. Sue B. Grimmond (iD ${ }^{2}$
}

The impact of feedback between urban warming and air-conditioning (AC) use on temperatures in future urban climates is explored in this study. Pseudo-global warming projections are dynamically downscaled to $1 \mathrm{~km}$ using a regional climate model (RCM) coupled to urban canopy and building energy models for current and six future global warming $\left(\Delta T_{\mathrm{GW}}\right)$ climates based on IPCC RCP8.5. Anthropogenic heat emissions from AC use is projected to increase almost linearly with $\Delta T_{\mathrm{GW}}$, causing additional urban warming. This feedback on urban warming reaches $20 \%$ of $\Delta T_{\mathrm{GW}}$ in residential areas. This further uncertainty in future projections is comparable in size to that associated with: a selection of emission scenarios, RCMs, and urban planning scenarios. Thus this feedback should not be neglected in future urban climate projections, especially in hot cities with large AC use. The impact of the feedback during the July 2018 Japanese heat waves is calculated to be $0.11^{\circ} \mathrm{C}$.

npj Climate and Atmospheric Science (2019)2:39

; https://doi.org/10.1038/s41612-019-0096-2

\section{INTRODUCTION}

With the global proportion of people living in cities expected to exceed two-thirds by $2050,{ }^{1}$ the urban climate affects many aspects of human life, including energy demand, health and the economy. Therefore, urban climate projections that include extreme weather events, such as heat waves from climate change, are of interest, given the potentially wide range of social and scientific impacts on human activities. These projections are also important when producing strategies to mitigate urban heat and for adapting to urban climate change. For example, given that US urban temperatures are predicted to increase by $1-2{ }^{\circ} \mathrm{C}$ due to climate change, energy demand is predicted to increase by 5-25\%. Therefore, effective adaptation strategies that include measures to cool the urban climate and built environment that do not result in further emissions of heat or greenhouse gases (GHGs) will need to be produced and assessed. ${ }^{2}$

Of the two main methods to obtain fine horizontal resolution projections of climate, the dynamical (rather than statistical) downscaling is used here. Several previous dynamical downscaling studies of future urban climate have used regional climate models (RCMs) with a coupled urban canopy model (UCM) (hereafter RCM/UCM). For example, Kusaka et al. ${ }^{3}$ predicted the 2070s summertime climate for three Japanese megacities using the Weather Research and Forecasting (WRF) model ${ }^{4}$ with the single-layer UCM, ${ }^{5,6}$ assuming pseudo-global warming (PGW), ${ }^{7,8}$ at a $3-\mathrm{km}$ resolution. This future climate projection (dynamical downscaling) method uses reanalysis data with the climatic change component from global climate models (GCMs; see 'Methods' section). Similar methods have been used for cities in Asia, ${ }^{9-11}$ Europe, $^{12,13}$ North America ${ }^{14,15}$ and Oceania. ${ }^{16}$ In these RCM/UCM studies, anthropogenic heat $\left(Q_{F}\right)$ is an important term in the urban surface heat balance but is assumed to have a constant diurnal pattern (e.g. Fig. 3 of Kusaka et al. ${ }^{17}$ ). Thus $Q_{F}$ impact on future urban temperatures is kept the same as current climate if all other factors (e.g. urban structure and human activities) do not change. This assumption may be reasonable in cities with little air-conditioning (AC) use (e.g. northern European cities); however, where AC use is already common (e.g. Asian cities), it may not.

If cities experience positive feedback from interactions between urban warming and AC use, ${ }^{18-21}$ this assumption would not hold. When air temperatures increase, energy consumption associated with AC use surges (Fig. 1a, Path 1) (i.e. increase in $Q_{F}$ from AC use $\left(Q_{F}, A C\right)$ ). In turn, the energy released outdoors will enhance urban warming (Fig. 1a, Path 2). ${ }^{22}$ Using a simple one-dimensional mixing-layer model, Ohashi et al. ${ }^{23}$ estimated the increase in summertime air temperature from AC waste heat in Osaka City to be +0.36 to $+0.72{ }^{\circ} \mathrm{C}$. Previous studies focus on only one side of this process. Most consider impacts of urban warming on energy consumption (Fig. 1a, Path 1). ${ }^{24-27}$ Effects of $Q_{F}$ on urban temperature (Fig. 1a, Path 2) have been studied with limitedarea models. ${ }^{28-33}$ However, the amount of 'additional warming' from urban warming-AC feedback has yet to be assessed. Hence, the impact of this feedback process on future urban climate remains unknown.

In this study, we define the temperature difference caused by $A C$ use as $\delta T_{\text {AC }}$ (Fig. 1b, orange):

$\delta T_{\mathrm{AC}}=\delta T_{\mathrm{AC} \neq \mathrm{FB}}+\delta T_{\mathrm{AC} \rightarrow \mathrm{FB}}$

where $\delta T_{A C \neq F B}$ is the temperature difference caused by $A C$ use but without $A C$ feedback (Fig. 1b purple, without Path 2 Fig. 1a [no- $Q_{F, A C}$ simulation], see 'Methods' [Model settings]). The 'additional temperature difference' caused by the feedback process is $\delta T_{\text {AC } \rightarrow \text { FB }}$ (Fig. 1b, green, with Path 2 Fig. 1a). In this study, we use model simulations to determine the different components (Fig. 1b and 'Methods' provide more details).

The Salamanca et al.'s ${ }^{22}$ WRF/BEP+BEM (building effect parameterisation and building energy model $)^{34-36}$ simulations, with and without $Q_{F, A C}$ release, allows $\delta T_{A C}$ to be estimated (Fig. $1 \mathrm{~b}$, reference (R) Salamanca et al., ${ }^{22} R_{S 14}$ ). The 10 -day Phoenix heat wave study obtained an extreme $\delta T_{A C}$ of $1.0^{\circ} \mathrm{C}$ at night. However, as they did not separate $\delta T_{A C}, \delta T_{A C \rightarrow F B}$ remains unknown. Given that $\delta T_{\mathrm{AC} \rightarrow \mathrm{FB}}$ may enhance electricity consumption (hereafter

\footnotetext{
${ }^{1}$ Environmental Management Research Institute, National Institute of Advanced Industrial Science and Technology, Tsukuba, Ibaraki, Japan. ${ }^{2}$ Department of Meteorology, University of Reading, Reading, UK. ${ }^{3}$ School of Science and Engineering, Meisei University, Hino, Tokyo, Japan. ${ }^{4}$ Center for Environmental Science in Saitama, Kazo, Saitama, Japan. *email: takane.yuya@aist.go.jp
} 

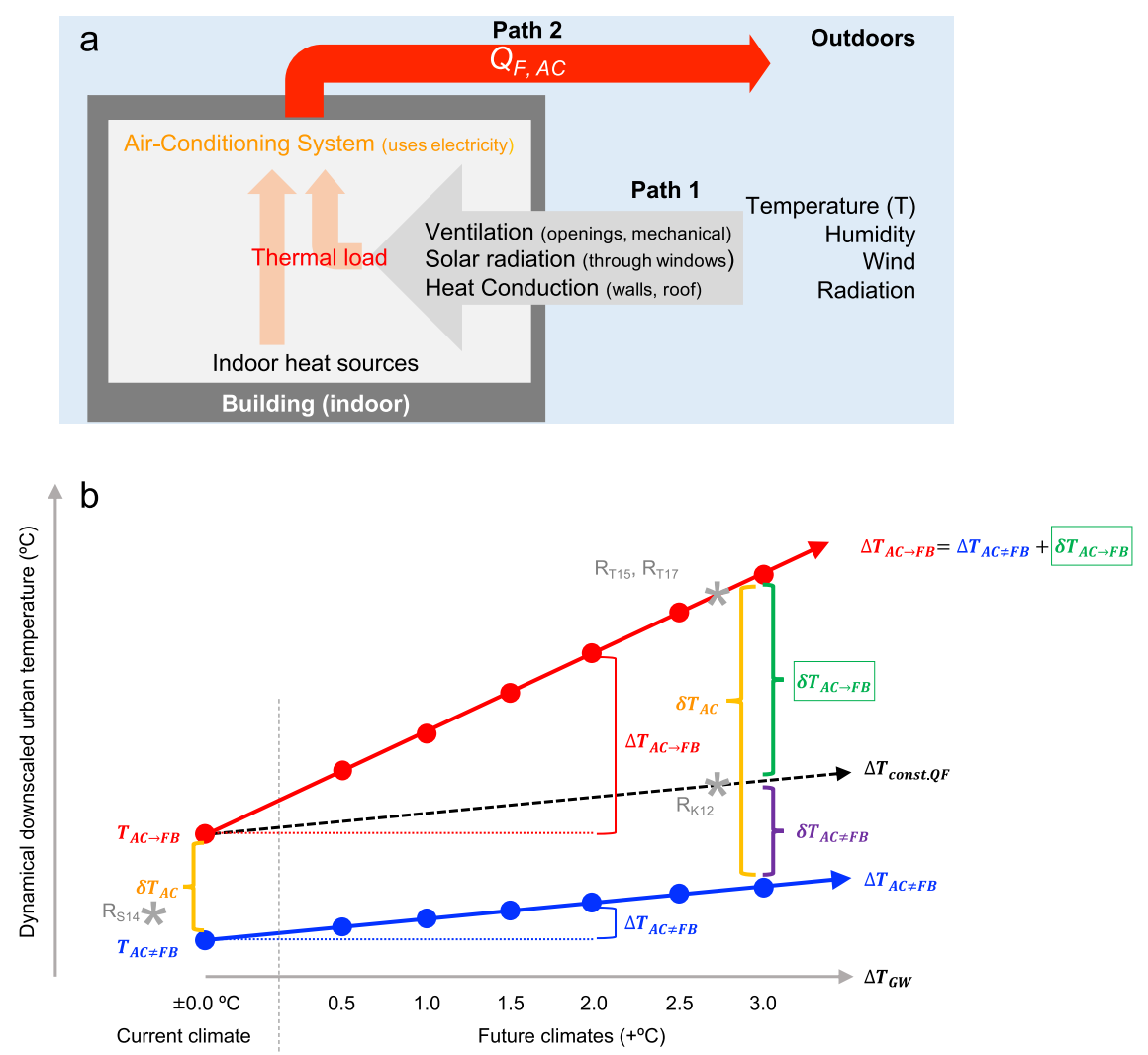

Fig. 1 Processes simulated through numerical experiments. a The interaction between the indoor energy use by air-conditioning (AC) can feedback (FB) on the outdoor environment (e.g. enhancing the temperature $T$, Path 2), which in turn enhances AC use (Path 1). b To evaluate these impacts, a series of simulations are undertaken: (i) control case ( $A C \rightarrow F B$ ) and (ii) no- $Q_{F}, A C$ case $(A C \neq F B)$, for current and future climates. From analysing the simulations, the trends (arrows) caused by global warming $\left(\Delta T_{\mathrm{GW}}\right)$ (grey), urban warming calculated by $\mathrm{AC} \rightarrow \mathrm{FB}\left(\Delta T_{\mathrm{AC}} \rightarrow \mathrm{FB}\right)$ (red) and $\mathrm{AC} \neq \mathrm{FB}\left(\Delta T_{\mathrm{AC} \neq \mathrm{FB}}\right)$ (blue) and urban warming if $Q_{\mathrm{F}, \mathrm{AC}}$ or $Q_{\mathrm{F}}$ in the future are the same as in the current climate ( $\left.\Delta T_{\text {const.OF }}\right)$ (black) are shown. Temperature differences are caused by $A C$ use (orange), anthropogenic heat emitted by $A C$ use without feedback (purple) and 'additional' impact of $Q_{F, A C}$ on temperature $\left(\delta T_{A C} \rightarrow F B\right)$, which are impacted by the 'additional' urban warming difference between the $A C \rightarrow F B$ and $\mathrm{AC} \neq \mathrm{FB}\left(\Delta T_{\mathrm{AC} \rightarrow \mathrm{FB}}\right.$ and $\left.\Delta T_{\mathrm{AC} \neq \mathrm{FB}}\right)$ (green). Climate simulations were undertaken for eleven August periods for current and future climates by $A C \rightarrow F B$ (red circles) and AC $\neq F B$ (blue circles). Approaches adopted by $R_{S 14}{ }^{22} R_{T 15},{ }^{40} R_{T 17}{ }^{43}$ and $R_{K 12}{ }^{3}$ (asterisks) are indicated. Inset shows feedback process caused by the interaction between outdoor weather change (urban warming due to climate change) and air-conditioning (AC) use. Here, $\Delta$ (e.g. $\Delta T$ ) is used to distinguish the difference between current and future climate and between cases with the same $\Delta T_{\mathrm{GW}}, \delta$ is used (e.g. $\delta T$ is temperature difference between $A C \rightarrow F B$ and $A C \neq F B$ at current climate or a future climate)

$\left.\delta E C_{\mathrm{AC} \rightarrow \mathrm{FB}}\right)$, we do not have a basis for understanding these changes with climate change (Fig. 1b, red).

With increases in both global temperatures ${ }^{37}$ and AC demand, ${ }^{38}$ it is important to explore this positive feedback phenomenon and evaluate its impact on the urban climate. Projected increases in AC demand and urban expansion may increase the feedback effect enhancing future projections uncertainties, whereas improved AC performance may offset demand from a warmer ambient environment. These could be as important as other uncertainties, such as the selection of emission scenarios, RCMs, urban planning scenarios and so on. Thus the feedback process consequently affects the impact assessment results and policy decisions associated with the Paris Agreement. ${ }^{39}$

Direct feedbacks can be calculated from climate projections for cities with AC usage when the RCM/UCM is coupled to a BEM. Electricity demand and summer thermal comfort projections for Nagoya in the $2070 \mathrm{~s}^{40}$ used WRF with coupled multi-layer UCM $(\mathrm{CM})^{41}$ and $\mathrm{BEM}^{19}\left(\mathrm{WRF} / \mathrm{CM}+\mathrm{BEM}^{42}\right.$ ) (Fig. 1b, $\left.\mathrm{R}_{\mathrm{T} 15}\right)$. Impacts of urban expansion and global warming on future urban temperatures and cooling demand for the Phoenix and Tucson metropolitan areas ${ }^{43}$ explored with WRF/BEP+BEM (Fig. 1b, $\mathrm{R}_{\mathrm{T} 17}$ ) did not assess the 'additional warming' from positive feedbacks $\left(\delta T_{\mathrm{AC} \rightarrow \mathrm{FB}}\right)$ (Fig. 1b, green) but did determine the amount of urban warming from current and future climate $(\Delta T)$ and the future electricity demand. This study addresses:
(1) What is the magnitude of the impact (and associated uncertainty) associated with such a feedback ( $\delta T_{A C \rightarrow F B}$ and $\delta E C_{A C \rightarrow F B}$ ) on future urban climate (Fig. 1b, green)?

(2) How is $\delta T_{\mathrm{AC} \rightarrow \mathrm{FB}}$ and $\delta E C_{\mathrm{AC} \rightarrow \mathrm{FB}}$ changed by climate change (i.e. increase/decrease, linear/nonlinear) (Fig. 1b, red)?

To address these, objectives WRF/BEP+BEM is used ('Methods'). From the results, we propose a simple parameterisation to account for $\delta T_{A C \rightarrow F B}$ and $\delta E C_{A C \rightarrow F B}$ in urban climate studies. We focus on Japan's second-largest megacity, Osaka (Fig. 2, Supplementary Fig. 2), as it experiences the warmest summertime mean temperatures in Japan. ${ }^{44}$ Osaka's humid climate (normal annual precipitation (1981-2010) is $1279 \mathrm{~mm}$ ) results in a more significant daytime urban heat island intensity than other dry climate cities. ${ }^{45}$

\section{RESULTS}

Changes in $Q_{F, A C}$ and urban air temperature $(\Delta T)$

The numerical model (see 'Methods') is verified (see Supplementary Note) for wooden detached dwellings, fireproof apartments and commercial and office buildings (hereafter simply office). Given the similarity of the results between the two dwelling types, only the fireproof apartments (hereafter simply residential) results are presented. 

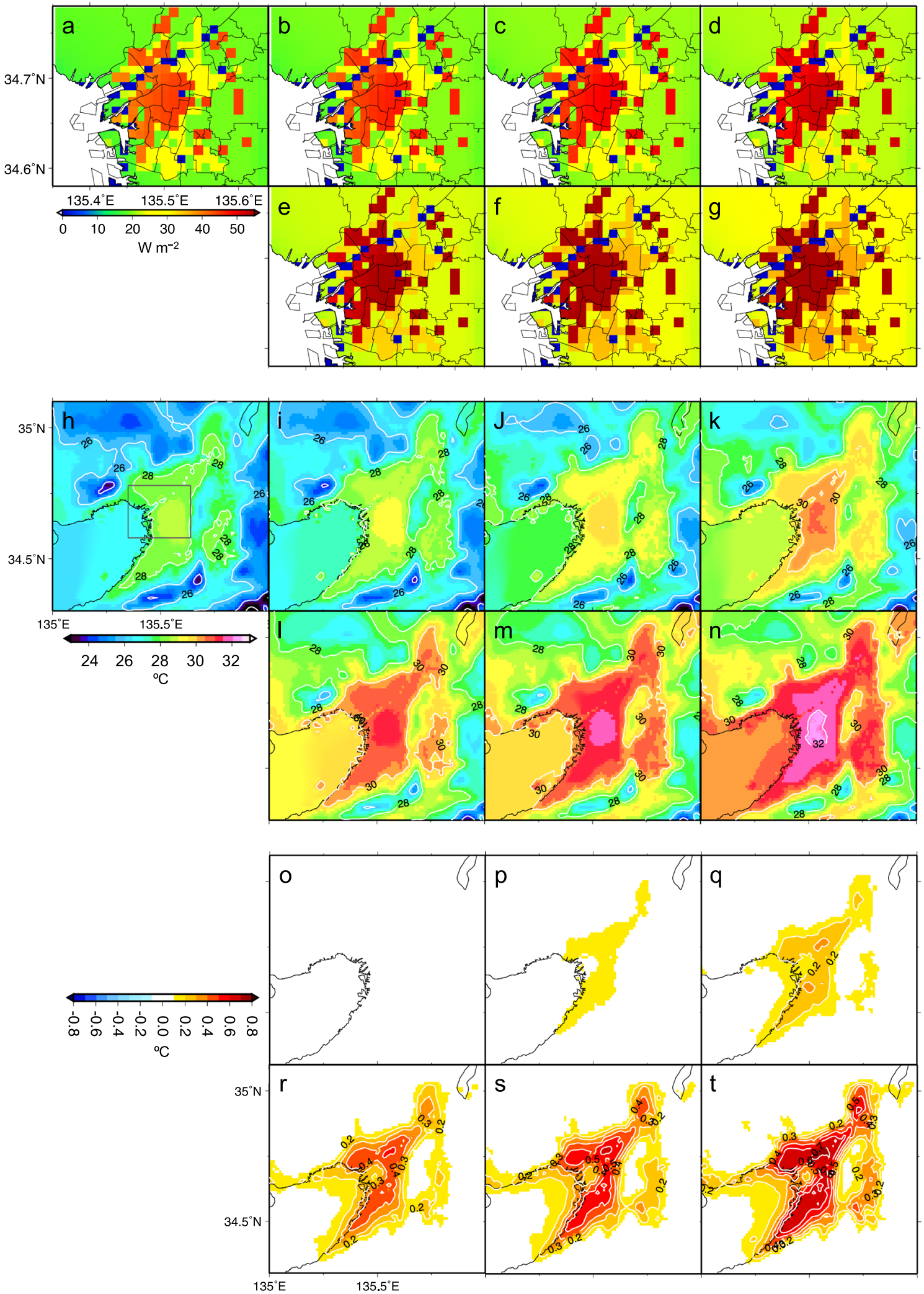

Fig. 2 Horizontal variation of August monthly mean (11 years) (a-g) anthropogenic heat flux $\left(Q_{\mathrm{F},} \mathrm{AC}\right),(\mathbf{h}-\mathbf{n}) 2 \mathrm{~m}$ air temperature and (o-t) $\delta T_{\mathrm{AC} \rightarrow \mathrm{FB}}$ : $\mathbf{a}-\mathbf{g}$ at 14:00 local time with city administrative boundaries (lines) of Osaka City (grey square in $\mathbf{h}$ ) for $\mathbf{a}$ current climate and $\Delta T_{\mathrm{GW}}, \mathbf{b}$ $+0.5^{\circ} \mathrm{C}, \mathbf{C}+1.0^{\circ} \mathrm{C}, \mathbf{d}+1.5^{\circ} \mathrm{C}, \mathbf{e}+2.0^{\circ} \mathrm{C}, \mathbf{f}+2.5^{\circ} \mathrm{C}$ and $\mathbf{g}+3.0^{\circ} \mathrm{C}$. $\mathbf{h}-\mathbf{n}$ As a-g, daily mean with contour intervals of $2^{\circ} \mathrm{C}$ (white lines). $\mathbf{0}-\mathbf{t}$ At $05: 00$ local time with contour interval $0.2^{\circ} \mathrm{C}$ (white lines) for $\mathbf{o}+0.5^{\circ} \mathrm{C}, \mathbf{p}+1.0^{\circ} \mathrm{C}, \mathbf{q}+1.5^{\circ} \mathrm{C}, \mathbf{r}+2.0^{\circ} \mathrm{C}, \mathbf{s}+2.5^{\circ} \mathrm{C}$ and $\mathbf{t}+3.0^{\circ} \mathrm{C}$ 


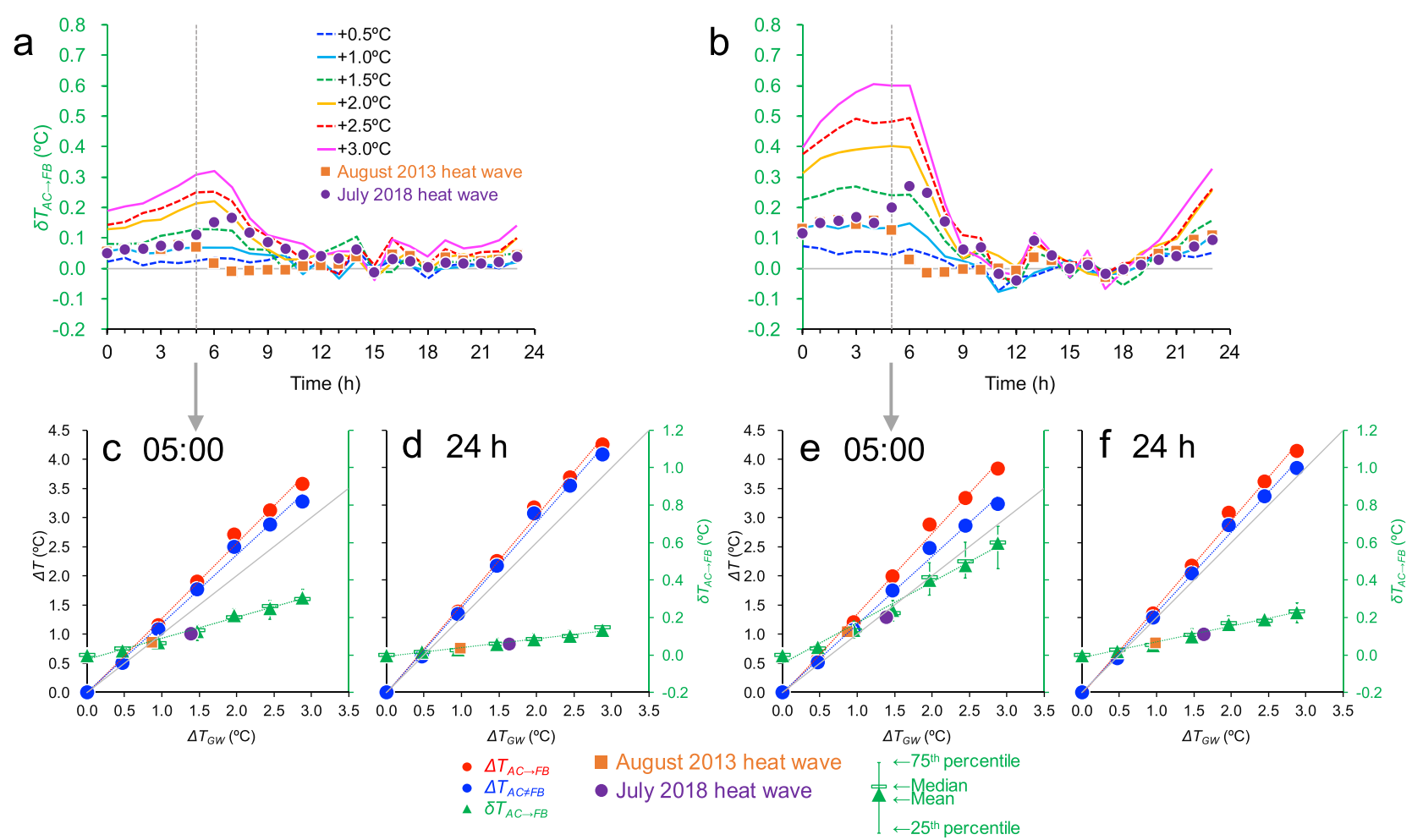

Fig. 3 Impact of the feedback process on air temperature $\left(\delta T_{A C \rightarrow F B}\right)$. a, b Diurnal variations of the $\delta T_{A C} \rightarrow F B$ for current climate (grey line, i.e. $0{ }^{\circ} \mathrm{C}$ ), six future climates simulated via $\Delta T_{\mathrm{GW}}$ and for heat waves in July 2018 (purple circles) and August 2013 (orange squares) in Japan estimated by linear relation between $\Delta T_{A C \rightarrow F B}$ and $\delta T_{A C \rightarrow F B}$ for each time (Table 2a) for $\mathbf{a}$ office and $\mathbf{b}$ residential areas. c-f Relation between $\Delta T_{\mathrm{GW}}$ and $\Delta T\left(\delta T_{\mathrm{AC} \rightarrow \mathrm{FB}}\right.$, green triangles) calculated from the $\mathrm{AC} \rightarrow \mathrm{FB}$ (red) and $\mathrm{AC} \neq \mathrm{FB}$ (blue) simulations for $\mathbf{c}$, $\mathbf{d}$ office and $\mathbf{e}, \mathbf{f}$ residential areas. c, e August 05:00 mean and d, f $24 \mathrm{~h}$ mean air temperatures. Regression lines (dotted). Error bars indicate 25th and 75th percentiles

The mean $Q_{F, A C}$ at 14:00 local time (LT) (i.e. close to a daily maximum of air temperature) in August is larger for office than residential areas for all seven control simulations (hereafter $A C \rightarrow$ FB) (Fig. $2 \mathrm{a}-\mathrm{g}$ and 'Methods'). $Q_{F, A C}$ increases from current to future climates $\left(\Delta Q_{F, A C}\right)$ as $\Delta T_{G W}$ increases, which is associated with additional $A C$ use (Fig. $2 \mathrm{a}-\mathrm{g}$ ) causing a close to linear increase in both the office $\left(\Delta Q_{F, A C} / \Delta T_{G W}=1.76 \mathrm{~W} \mathrm{~m}^{-2}{ }^{\circ} \mathrm{C}^{-1}\right)$ and residential areas $\left(3.32 \mathrm{~W} \mathrm{~m}^{-2}{ }^{\circ} \mathrm{C}^{-1}\right)$. When $\Delta T_{\mathrm{GW}}$ is $+3.0^{\circ} \mathrm{C}, \Delta Q_{\mathrm{F}, \mathrm{AC}}$ is 1.37 (office) to 1.81 (residential) times larger than for current climate conditions (Supplementary Table 1).

The mean August $2 \mathrm{~m}$ air temperature ( $24 \mathrm{~h}, 11$ years) in Osaka is warmer than the surrounding areas in both current and future climates (Fig. $2 \mathrm{~h}-\mathrm{n}$ ). The temperature difference between the $A C \rightarrow F B$ and the no- $Q_{F}, A C$ case $(A C \neq F B)$ simulations increases along with $\Delta T_{\mathrm{GW}}$ (Fig. 3), indicating that urban heat will increase over time. This is caused by $\Delta Q_{F, A C}$ with larger differences in the residential than in the office areas.

The differences between simulations with $\left(\Delta T_{\mathrm{AC} \rightarrow \mathrm{FB}}\right)$ and without $\left(\triangle T_{\mathrm{AC} \neq \mathrm{FB}}\right)$ anthropogenic heat fluxes allows the $\delta T_{\mathrm{AC} \rightarrow \mathrm{FB}}$ to be determined (Figs. 1a 20-t and 3). The $\delta T_{A C \rightarrow F B}(05: 00,11$ August months) and $\Delta T_{\mathrm{GW}}$ increase and the $\delta T_{\mathrm{AC} \rightarrow \mathrm{FB}}$ in Osaka's surrounding areas are higher than those of the centre of Osaka in both current and future climates (Fig. 20-t). The diurnal variation of the $\delta T_{\mathrm{AC} \rightarrow \mathrm{FB}}$ in residential areas (Fig. 3b) has two main features:

(1) $\delta T_{\mathrm{AC} \rightarrow \mathrm{FB}}$ for current and future climates are relatively small during daytime (notably 09:00-18:00) but larger at night (notably 18:00-06:00), with a peak around 05:00; and

(2) $\delta T_{\mathrm{AC} \rightarrow \mathrm{FB}}$ increases gradually as $\Delta T_{\mathrm{GW}}$ increases $\left(+0.5^{\circ} \mathrm{C}\right.$ to $+3.0^{\circ} \mathrm{C}$ ) during the night, indicating that urban warmth will increase overnight.

The relatively small daytime $\delta T_{A C} \rightarrow F B$, despite the relatively large daytime $Q_{F, A C}$ is because of the relatively high daytime mixed layer. As $Q_{F, A C}$ is mixed in a large volume, the impact of $Q_{F}$, AC on surface air temperature is reduced. At night, $Q_{F, A C}$ is smaller, but the mixed layer height is lower. Similar results in previous work ${ }^{31}$ support this proposed mechanism.

The relation between $\Delta T_{\mathrm{GW}}$ and downscaled urban warming $\left(\Delta T_{\mathrm{AC} \rightarrow \mathrm{FB}}\right.$ and $\left.\Delta T_{\mathrm{AC} \neq \mathrm{FB}}\right)$ has two main features for office areas (Fig. 3d):

(1) $\delta T_{\mathrm{AC} \rightarrow \mathrm{FB}}$ tends to increase linearly with $\Delta T_{\mathrm{GW}}$. This increase is from a feedback: $\Delta T_{\mathrm{GW}}$ modifies $\Delta Q_{\mathrm{F}, \mathrm{AC}}$, contributing to additional urban warming (Fig. 1a, Path $1 \rightarrow$ Path 2)

$$
\Delta T_{G W} \rightarrow \Delta Q_{F, A C} \rightarrow \delta T_{A C \rightarrow F B}
$$

(2) $\Delta T_{\mathrm{AC} \rightarrow \mathrm{FB}}$ has a linear trend, as does $\Delta T_{\mathrm{AC} \neq \mathrm{FB}}$.

This is the first study to estimate the 'additional' positive feedback impact on future climate associated with AC. We conclude that $\Delta T_{\mathrm{AC} \rightarrow \mathrm{FB}}$ has an approximately linear trend (Fig. $3 \mathrm{C}-\mathrm{f}$, red). The resulting $\mathrm{AC} \rightarrow \mathrm{FB}$ case slope $\left(\Delta T_{\mathrm{AC} \rightarrow \mathrm{FB}} / \Delta T_{\mathrm{GW}}\right)$ is $1.18^{\circ} \mathrm{C}^{\circ} \mathrm{C}^{-1}$ for the office areas. This is larger than for the $A C \neq F B$ case $\left(1.13^{\circ} \mathrm{C}^{\circ} \mathrm{C}^{-1}\right)$. These results suggest that it is relatively easy to estimate (parameterise) the impact of the feedback.

The two features in the monthly mean (Fig. 3d) are more evident at 05:00 (Fig. 3C) with $\Delta T_{\mathrm{AC} \rightarrow \mathrm{FB}} / \Delta T_{\mathrm{GW}}=1.29^{\circ} \mathrm{C}^{\circ} \mathrm{C}^{-1}$, which is larger than for case $A C \neq F B\left(1.17^{\circ} \mathrm{C}^{\circ} \mathrm{C}^{-1}\right)$. At 14:00 feature (1), $\Delta T_{\mathrm{AC} \rightarrow \mathrm{FB}}$ and $\Delta T_{\mathrm{AC} \neq \mathrm{FB}}$ are essentially the same, and $\delta T_{\mathrm{AC} \rightarrow \mathrm{FB}}$ does not increase with $\Delta T_{\mathrm{GW}}$.

The daily average of normalised $\delta T_{\mathrm{AC} \rightarrow \mathrm{FB}}$ (see 'Methods') is roughly constant (3-5\%) and not dependent on $\Delta T_{\mathrm{GW}}$ for the office area (Supplementary Fig. 1a). The average of normalised $\delta T_{\mathrm{AC} \rightarrow \mathrm{FB}}$ at $05: 00$ increases from $3 \%\left(+0.5^{\circ} \mathrm{C}\right)$ to $10 \%\left(+3.0^{\circ} \mathrm{C}\right)$ as $\Delta T_{\mathrm{GW}}$ increases (Supplementary Fig. 1a, Supplementary Table 1). 
Results for the residential area are similar to the office area, but feature (1) is more evident, especially at 05:00 (Fig. 3e, f). The $\Delta T_{\mathrm{AC} \rightarrow \mathrm{FB}} / \Delta T_{\mathrm{GW}}\left(1.38^{\circ} \mathrm{C}^{\circ} \mathrm{C}^{-1}\right)$ is larger than the $\mathrm{AC} \neq \mathrm{FB}$ case $\left(1.16^{\circ} \mathrm{C}^{\circ} \mathrm{C}^{-1}\right)$. As $A C$ is used $24 \mathrm{~h}$ per day in residential areas, this cumulatively contributes more to warming than in office areas. The daily average of normalised $\delta T_{\mathrm{AC} \rightarrow \mathrm{FB}}$ increases slightly from +0.5 to $+3.0^{\circ} \mathrm{C}$, reaching $8 \%$ (at $+3.0^{\circ} \mathrm{C}$ ). Thus about $0.25^{\circ} \mathrm{C}$ additional urban warming is caused by the feedback when $\Delta T_{\mathrm{GW}}$ is $+3.0^{\circ} \mathrm{C}$ in the residential area. The normalised $\delta T_{A C} \rightarrow F B$ at 05:00 increases from $8 \%$ (at $+0.5^{\circ} \mathrm{C}$ ) to $20 \%$ (at $+3.0^{\circ} \mathrm{C}$ ). This means that about $0.6^{\circ} \mathrm{C}$ additional urban warming is caused by the feedback when $\Delta T_{\mathrm{GW}}$ is $+3.0^{\circ} \mathrm{C}$ (Fig. 3e).

\section{DISCUSSION}

Importance of the feedback in adapting to future urban climate change

The choice of emission scenario causes uncertainty in projections. For example, the 2070s August mean urban temperatures in Osaka in the Intergovernmental Panel on Climate Change (IPCC) Special Report on Emissions Scenarios with the A2 scenario projected $0.3^{\circ} \mathrm{C}$ higher than $\mathrm{A} 1 \mathrm{~b} .{ }^{46}$ Doan and Kusaka's ${ }^{11}$ urban warming projections (current to 2050s) for greater Ho Chi Minh City based on IPCC representative concentration pathway 4.5 (RCP4.5) and RCP8.5 scenarios found different scenarios to cause urban warming differences of $0.5^{\circ} \mathrm{C}$. The feedback uncertainty $\left(\sim 0.25^{\circ} \mathrm{C}\right.$ for residential areas when $\left.\Delta T_{\mathrm{GW}}=+3.0^{\circ} \mathrm{C}\right)$ is comparable to these emission scenario differences of 0.3 and $0.5^{\circ} \mathrm{C}$, respectively (Table $1 \mathrm{a}$ ). Further uncertainty arises from the RCM choice. Kusaka et al.'s ${ }^{10}$ August 2050s urban temperature projections in central Tokyo, using WRF and NHRCM (nonhydrostatic model of the Japan Meteorological Agency ${ }^{47}$ ), had a 10 -year mean temperature increase uncertainty between RCMs of $\sim 0.2^{\circ} \mathrm{C}$ (i.e. like the feedback reported here, see Table $1 \mathrm{a}$ ).

Our work shows $\delta T_{A C \rightarrow F B}$ could reach $0.25^{\circ} \mathrm{C}$ in residential areas. This is comparable to the $0.3-0.5^{\circ} \mathrm{C}_{\text {century }}{ }^{-1}$ estimated global warming in Japan. ${ }^{48}$ This feedback impact of $0.25^{\circ} \mathrm{C}$ in residential areas is comparable to urban planning scenarios (Adachi et al., ${ }^{49}$ Kusaka et al. ${ }^{10}$ ) for 'dispersed' ( 0.34 and $0.1^{\circ} \mathrm{C}$, respectively) and 'compact' ( $\sim 0.1$ and $0.4{ }^{\circ} \mathrm{C}$, respectively) cities and future urbanisation on temperature of $0.5^{\circ} \mathrm{C}^{11}$ (Table 1a).

The feedback impact is small in the daytime but large nocturnally, increasing with $\Delta T_{G W}$ (Fig. 3). The normalised $\delta T_{\mathrm{AC} \rightarrow \mathrm{FB}}$ at $05: 00$ increases with $\Delta T_{\mathrm{GW}}: 10 \%$ in the office areas and $20 \%$ in the residential areas, when $\Delta T_{\mathrm{GW}}$ is $+3.0^{\circ} \mathrm{C}$ (Supplementary Fig. 1). These results suggest that mitigating the feedback process before the impact becomes large may be an effective strategy to adapt to climate change in cities as the feedback effect could be comparable to those of past global warming, affecting urban planning scenarios. For example (Supplementary Discussion), the feedback uncertainty for a $\Delta T_{\mathrm{GW}}$ of $+2.0^{\circ} \mathrm{C}$ is $\sim 10$ years (Fig. $4 b$, Table 1 b), if we can stop the feedback technologically (e.g. improved coefficient of performance (COP), geothermal energy use) we could postpone a $+2.0^{\circ} \mathrm{C}$ world by about 10 years.

Application: $\delta T_{\mathrm{AC} \rightarrow \mathrm{FB}}$ and $\delta E C_{\mathrm{AC} \rightarrow \mathrm{FB}}$ estimates for the recent heat waves in Japan

As shown ('Results'), $\Delta T_{\mathrm{AC} \rightarrow \mathrm{FB}}$ and $\delta T_{\mathrm{AC} \rightarrow \mathrm{FB}}$ have near linear trends with $\Delta T_{\mathrm{GW}}$. Also $\delta T_{\mathrm{AC} \rightarrow \mathrm{FB}}$ and $\delta E C_{\mathrm{AC} \rightarrow \mathrm{FB}}$ are close to linear with $\Delta T_{\mathrm{AC} \rightarrow \mathrm{FB}}$. This suggests that to estimate (parameterise) $\delta T_{\mathrm{AC} \rightarrow \mathrm{FB}}$ and $\delta E C_{\mathrm{AC} \rightarrow \mathrm{FB}}$ for other future urban climates or for specific events (e.g. heat waves) is straightforward. Table 2 shows gradients $(a)$ of linear regression $(y=a x)$ between $\Delta T_{\mathrm{AC} \rightarrow \mathrm{FB}}(x)$ and $\delta T_{A C \rightarrow F B}\left(\delta E C_{A C \rightarrow F B}\right)(y)$. Here we estimate the $\delta T_{A C \rightarrow F B}$ and $\delta E C_{A C \rightarrow F B}$ for the recent heat waves of July 2018 and August 2013 in Japan using our proposed linear relations to illustrate an application.

The 2013 summer was the warmest on record for Japan (statistics since $1946^{50}$ ), with $41.0^{\circ} \mathrm{C}$ recorded in western Japan (Shimanto City). In Osaka City, the August monthly mean $\left(30.0^{\circ} \mathrm{C}\right)$ was $0.99^{\circ} \mathrm{C}$ higher than the 11 -year mean (2000-2010). July 2018 was one of the hottest Julys in Japan since 1946, with Osaka's monthly mean temperature $\left(29.5^{\circ} \mathrm{C}\right) 1.63^{\circ} \mathrm{C}$ higher than the 11 year mean (2000-2010). Therefore, August 2013 and July 2018 roughly correspond to situations when $\Delta T_{\mathrm{AC} \rightarrow \mathrm{FB}}=+1.0^{\circ} \mathrm{C}$ and $+1.5^{\circ} \mathrm{C}$, respectively. Figure $3 \mathrm{a}$, b shows a diurnal variation of the $\delta T_{\mathrm{AC} \rightarrow \mathrm{FB}}$ for the two heat waves estimated by linear relations (Table 2a). The $\delta T_{A C \rightarrow F B}$ for the two heat waves during the night to morning are higher than that for the daytime, especially in the residential areas. The $24-\mathrm{h}$ mean $\delta T_{\mathrm{AC} \rightarrow \mathrm{FB}}$ for July 2018 is $0.11^{\circ} \mathrm{C}$ in the residential areas, which is higher than the $0.07^{\circ} \mathrm{C}$ of August 2013. Similarly, the 24-h mean $\delta E C_{A C} \rightarrow F B$ for July 2018 is $0.05 \mathrm{~W}$ floor- $\mathrm{m}^{-2}$, which is higher than $0.03 \mathrm{~W}$ floor- $\mathrm{m}^{-2}$ of August 2013. Estimates of $\delta T_{\mathrm{AC} \rightarrow \mathrm{FB}}$ and $\delta E C_{\mathrm{AC} \rightarrow \mathrm{FB}}$ could be easily assessed for other heat waves and/or future urban climates in hot cities where significant $A C$ use is common.

\section{Summary}

Here a positive feedback from the interaction between urban warming and $A C$ use is identified and quantified. Analysis of simulations for current and six future climate scenarios (global warming: $\Delta T_{\mathrm{GW}}$ ) is undertaken. For the latter, CMIP5 GCMs simulations with the highest IPCC GHG emissions scenario (RCP8.5) were used. The megacity of Osaka is analysed for August when AC use is at its greatest. From this, it is concluded that:

(i) Anthropogenic heat emissions from $\mathrm{AC}$ use $\left(Q_{\mathrm{F}, \mathrm{AC}}\right)$ are predicted to increase linearly with $\Delta T_{\mathrm{GW}}$ from current to future climates. Monthly total $Q_{F, A C}$ in commercial \& office and residential areas are projected to be 1.37 and 1.81 times larger than current climate conditions when $\Delta T_{\mathrm{GW}}$ is $+3.0^{\circ} \mathrm{C}$, respectively;

(ii) This represents a feedback process from current to future climate:

$\Delta T_{\mathrm{GW}} \rightarrow \Delta Q_{\mathrm{F}, \mathrm{AC}}\left(Q_{\mathrm{F}, \mathrm{AC}}\right.$ increase) $\rightarrow \delta T_{\mathrm{AC} \rightarrow \mathrm{FB}}$ ('additional' temperature increase from the feedback)

Urban warming calculated when anthropogenic heat fluxes are permitted [case $\mathrm{AC} \rightarrow \mathrm{FB}\left(\Delta T_{\mathrm{AC} \rightarrow \mathrm{FB}}\right)$ ] is greater than when they are not included [case $A C \neq F B\left(\Delta T_{A C \neq F B}\right)$ ]. The difference between these two $\left[\Delta T_{\mathrm{AC} \rightarrow \mathrm{FB}}-\Delta T_{\mathrm{AC} \neq \mathrm{FB}}\right]$ provides $\delta T_{\mathrm{AC} \rightarrow \mathrm{FB}}$. This increases almost linearly with $\Delta T_{\mathrm{GW}}$ suggesting urban temperatures will increase faster than global warming due to the increase of the anthropogenic heating (assuming all other characteristics of the city remain constant) in future climates. The normalised $\delta T_{\mathrm{AC} \rightarrow \mathrm{FB}}$ at 05:00 (LT) has the larger increase with $\Delta T_{\mathrm{GW}}$. This reaches $10 \%$ of $\Delta T_{\mathrm{GW}}$ in office areas and $20 \%$ in residential area. Thus about $0.3^{\circ} \mathrm{C}$ (office) and $0.6^{\circ} \mathrm{C}$ (residential) additional urban warming is caused by the feedback when $\Delta T_{\mathrm{GW}}$ is $+3.0^{\circ} \mathrm{C}$. The $\delta T_{\mathrm{AC} \rightarrow \mathrm{FB}}$ is expected to increase $E C$ through a feedback process:

$\Delta T_{\mathrm{GW}} \rightarrow \Delta Q_{\mathrm{F}, \quad \mathrm{AC}} \rightarrow \delta T_{\mathrm{AC} \rightarrow \mathrm{FB}} \rightarrow \delta E C_{\mathrm{AC} \rightarrow \mathrm{FB}} \quad$ ('additional' $E C$ increase from the feedback).

The $E C$ increase calculated by case $\mathrm{AC} \rightarrow \mathrm{FB}\left(\triangle E C_{\mathrm{AC} \rightarrow \mathrm{FB}}\right)$ is greater than that calculated by case $A C \neq F B\left(\triangle E C_{A C \neq F B}\right)$. The difference between these $\left(\triangle E C_{\mathrm{AC} \rightarrow \mathrm{FB}}-\triangle E C_{\mathrm{AC} \neq \mathrm{FB}}\right)$ : $\delta E C_{\mathrm{AC} \rightarrow \mathrm{FB}}$ increased linearly with $\Delta T_{\mathrm{GW}}$; 
Table 1. Uncertainties in summer urban climate simulation projections: a Temperatures and $\mathbf{b}$ time (years) for the indicated warming to occur with the GCMs and the feedback

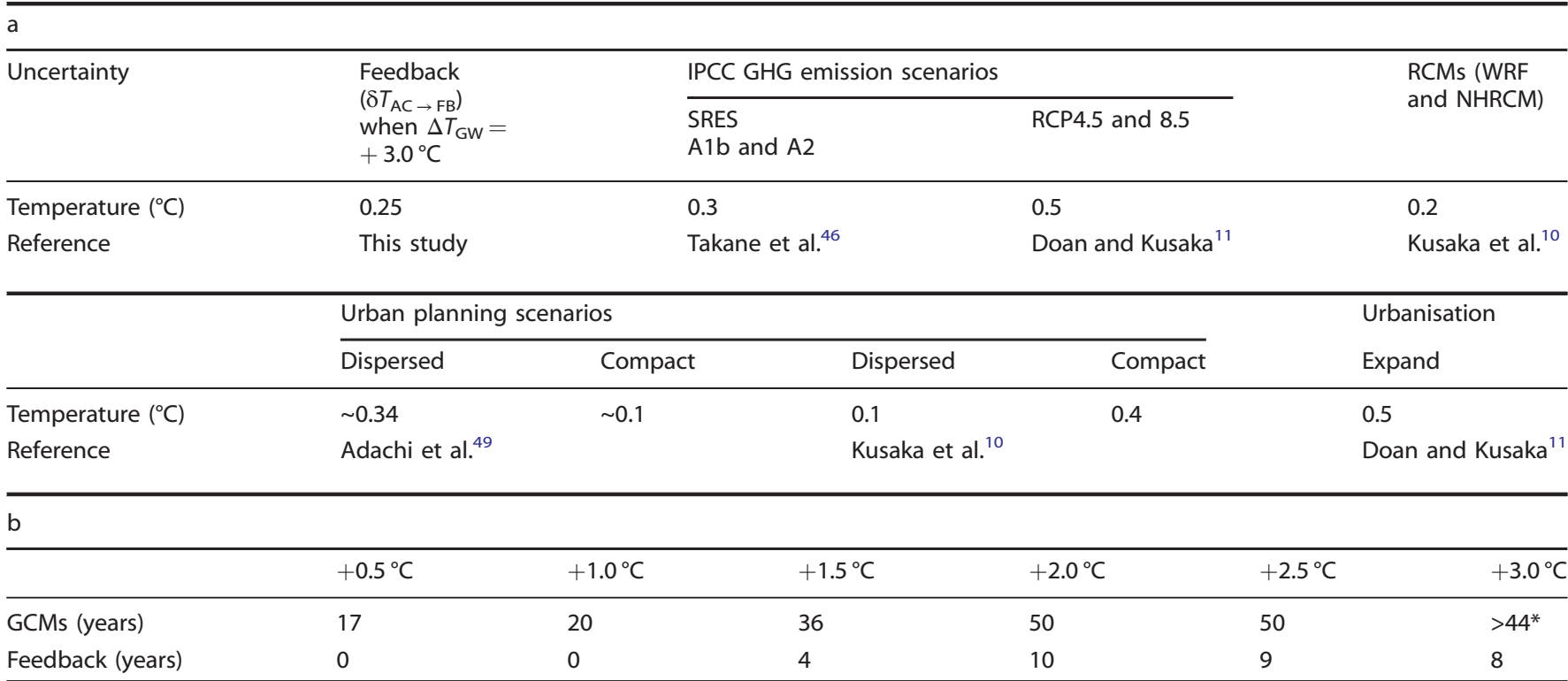

${ }^{*}$ Calculated from three GCMs (see Supplementary Discussion)

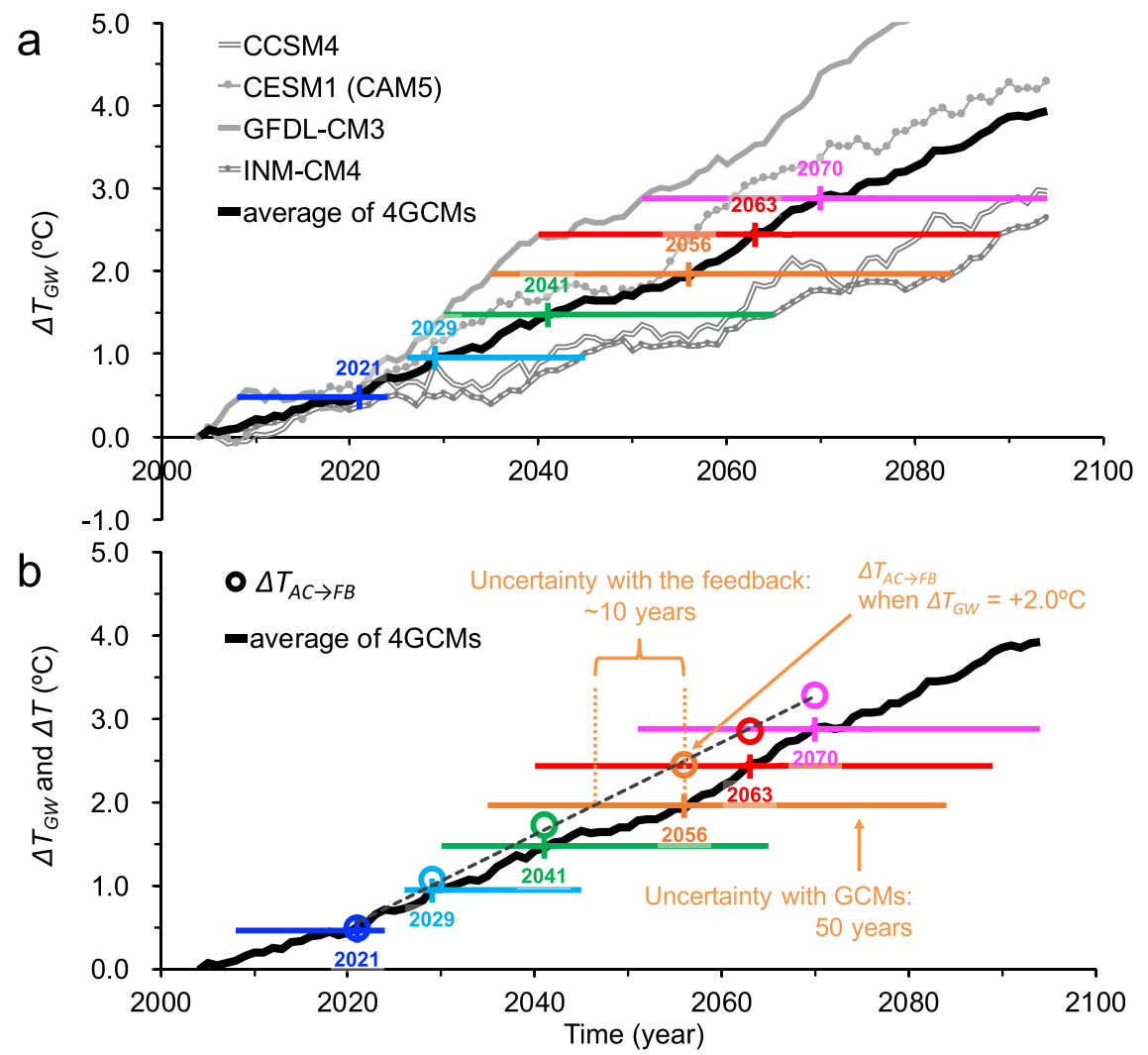

Fig. 4 Changes in August mean surface air temperature for Japan. a Projected increase compared to 2000s (decadal running averages) for four global climate models (CCSM4, CESM1 (CAM5), GFDL-CM3 and INM-CM4; for references, see 'Methods') and the average $\Delta T_{\mathrm{GW}}$ (black line) for four GCMs assuming the RCP8.5 scenario (see text for more details). b Time series of $\Delta T_{\mathrm{GW}}$ (thick black line) and $\Delta T_{\mathrm{AC} \rightarrow F B}$ (circles) with maximum uncertainties (colour lines) of four GCMs and linear approximation of $\Delta T_{A C \rightarrow F B}$ (dashed black line). Values are averaged for three urban categories: commercial and office buildings, fireproof apartments, and wooden detached dwellings 
Table 2. Gradients of linear regression (sensitivities) between $\mathbf{a} \Delta T_{\mathrm{AC} \rightarrow \mathrm{FB}}$ and $\delta T_{\mathrm{AC} \rightarrow \mathrm{FB}}\left({ }^{\circ} \mathrm{C}^{\circ} \mathrm{C}^{-1}\right)$ by time of day and location and between $\mathbf{b} \Delta T_{\mathrm{AC} \rightarrow \mathrm{FB}}$ and $\delta E C_{A C \rightarrow F B}\left(W\right.$ floor $\left.-\mathrm{m}^{-2}{ }^{\circ} \mathrm{C}^{-1}\right)$

a

\begin{tabular}{|c|c|c|c|c|c|c|c|c|}
\hline Time (h) & 0 & 1 & 2 & 3 & 4 & 5 & 6 & 7 \\
\hline Office & 0.0496 & 0.0532 & 0.0575 & 0.0633 & 0.0714 & 0.0796 & 0.0808 & 0.0681 \\
\hline Residential & 0.1168 & 0.1302 & 0.1391 & 0.1455 & 0.1458 & 0.1434 & 0.1436 & 0.1027 \\
\hline Time (h) & 8 & 9 & 10 & 11 & 12 & 13 & 14 & 15 \\
\hline Office & 0.0429 & 0.0326 & 0.0231 & 0.0170 & 0.0152 & 0.0133 & 0.0285 & -0.0080 \\
\hline Residential & 0.0554 & 0.0234 & 0.0243 & -0.0066 & -0.0147 & 0.0378 & 0.0197 & -0.0006 \\
\hline
\end{tabular}

\begin{tabular}{llllllllll}
\hline Time $(\mathrm{h})$ & 16 & 17 & 18 & 19 & 20 & 21 & 22 & 23 & Mean \\
\hline Office & 0.0253 & 0.0205 & 0.0033 & 0.0202 & 0.0157 & 0.0181 & 0.0213 & 0.0358 & 0.0367 \\
Residential & 0.0101 & -0.0158 & -0.0036 & 0.0113 & 0.0297 & 0.0443 & 0.0701 & 0.0923 & 0.0673
\end{tabular}

b

\begin{tabular}{lllllllll}
\hline Time (h) & 0 & 1 & 2 & 3 & 4 & 5 & 6 & 7 \\
\hline Office & 0 & 0 & 0 & 0 & 0 & 0 & 0 & 0 \\
Residential & 0.0364 & 0.0834 & 0.1010 & 0.1160 & 0.1193 & 0.1223 & 0.1137 & 0.1003 \\
\hline Time (h) & 8 & 9 & 10 & 11 & 12 & 13 & 14 & 0.0353 \\
\hline Office & 0 & -0.0182 & 0.0469 & 0.0326 & 0.0194 & 0.0759 & 0.0231 \\
Residential & 0.0631 & 0.0383 & 0.0134 & 0.0052 & 0.0008 & 0.0017 & 0.0028 & -0.0032 \\
\hline Time (h) & 16 & 17 & 18 & 19 & 20 & 21 & 22 & 23 \\
\hline Office & 0.0297 & 0.0192 & 0.0187 & 0.0166 & 0 & 0 & 0 & 0 \\
Residential & 0.0026 & -0.0006 & -0.0021 & -0.0010 & 0.0040 & 0.0005 & -0.0084 & 0.0101 \\
\hline
\end{tabular}

*Mean when $A C$ in use

(iii) Uncertainty introduced by the feedback $\left(\delta T_{\mathrm{AC} \rightarrow \mathrm{FB}}\right)$ is comparable to that introduced from selection of emission scenario, RCM and/or urban planning scenario. Thus this feedback should not be neglected in future urban climate projection, especially in hot cities where significant AC use is common; and

(iv) Using linear relations proposed in this study (between $\Delta T_{\mathrm{AC} \rightarrow \mathrm{FB}}$ and $\left.\delta T_{\mathrm{AC} \rightarrow \mathrm{FB}}\right)$, the $\delta T_{\mathrm{AC} \rightarrow \mathrm{FB}}$ during recent Japanese heat waves (July 2018 and August 2013) are estimated to be 0.11 and $0.07^{\circ} \mathrm{C}$, respectively. Such an approach can be used to estimate $\delta T_{A C \rightarrow F B}$ for other heat waves and/or future urban climates in hot cities where significant $A C$ use is common.

\section{METHODS}

To distinguish the difference between current and future climate $\Delta$ (e.g. $\Delta T$ ) is used, and between cases with the same $\Delta T_{\mathrm{GW}}, \delta$ is used (e.g. $\delta T$ is a temperature difference between $\mathrm{AC} \rightarrow \mathrm{FB}$ and $\mathrm{AC} \neq \mathrm{FB}$ (explained later) at current climate or a future climate).

First, the impacts of the feedback $\left(\delta T_{\mathrm{AC} \rightarrow \mathrm{FB}}\right)$ on future urban climate from global temperature scenarios (hereafter $\Delta T_{\mathrm{GW}}$ ) are evaluated. Second, we explore how $\delta T_{\mathrm{AC} \rightarrow \mathrm{FB}}$ changes in relation to $\Delta T_{\mathrm{GW}}$. The urban air temperature and $E C$ calculated by $\mathrm{WRF} / \mathrm{BEP}+\mathrm{BEM}$ were verified using detailed observational data for a year. ${ }^{51}$
Description of the numerical model

Previously, WRF/BEP+BEM simulated urban air temperature and EC for April 2013 to March 2014 in Osaka were verified. ${ }^{51}$ The modified model reproduced current diurnal and horizontal variations of $2 \mathrm{~m}$ urban air temperature and $E C$ at a 1 -h temporal resolution for 12 electric power substations within Osaka City (about $1 \mathrm{~km}^{2}$ area).

At each time step, $Q_{F, A C}$ is calculated for each grid as: ${ }^{19,51}$

$Q_{\mathrm{F}, \mathrm{AC}}=\left(H_{\text {out }}+E_{\text {out }}\right)+E C=\frac{\mathrm{COP}+1}{\mathrm{COP}}\left(H_{\text {out }}+E_{\text {out }}\right)$

where $H_{\text {out }}$ and $E_{\text {out }}$ are the sensible and latent heat supplied from the AC system for cooling (see section 2.5 of Salamanca et al. ${ }^{35}$ ), respectively, and COP is the coefficient of performance. The $H_{\text {out }}$ and $E_{\text {out }}$ are calculated from the total sensible, $H_{\text {in }}$ and latent, $E_{\text {in }}$, heat loads per floor. ${ }^{35}$ The $H_{\text {in }}$ considers four physical processes: (1) solar radiation through the window and the heat exchange between the windows and the indoor air, (2) heat conduction through the walls and heat exchange between the wall, ceiling and pavement and the indoor air, (3) sensible heat exchange through ventilation, and (4) the internal sensible heat generation from equipment and occupants (Fig. 1a). Outdoor weather directly affects the $H_{\text {in }}$ through processes (1-3), and the affected $H_{\text {in }}$ contributes to an increase in $Q_{F, A C}$ and $E C$ through the $H_{\text {out }}$ (Fig. 1a Path 1). Here $Q_{F, A C}$ is split into sensible heat $Q_{F, A C, S}$ and latent heat, $Q_{F, A C, L}$ as commercial and office building areas are considered ${ }^{52}$

$Q_{\mathrm{F}, \mathrm{AC}, \mathrm{S}}=0.722 Q_{\mathrm{F}, \mathrm{AC}}$

$Q_{F, A C, L}=0.278 Q_{F, A C}$ 
The WRF/BEP+ BEM model system assumptions include: ${ }^{51}$ (1) individual AC units exist (using a simple parameterisation); (2) a constant COP (implications discussed in Supplemental information) occurs; (3) no $Q_{F}$ from traffic occurs; and (4) only typical weekdays occur. Therefore, the results of this study are for these conditions (i.e. weekdays).

Although $Q_{F}$ from traffic $\left(Q_{F, \text { traffic }}\right)$ is important ${ }^{53,54}$ in some cities, in Osaka ${ }^{42,52} Q_{F, A C}$ is at least two times larger. As traffic is already common in Asian megacities, while AC demand is dramatically increasing ${ }^{38}$ (e.g. in Vietnam penetration rates of $A C$, motorcar and motorbike are $10.8 \%$, $77.4 \%$, and $81.8 \%$, respectively $\left.{ }^{55}\right), Q_{F, A C}$ has the potential to be a big problem in the future (cf. $Q_{F, \text { traffic }}$ ) but will benefit from COP increases. Future studies will consider $Q_{F \text {,AC }}$ and $Q_{F}$ traffic using models such as WRF/ $\mathrm{CM}+\mathrm{BEM} .^{42}$ However, the conclusions of this report are not impacted by $Q_{F \text { traffic }}$ as it is assumed to be constant and uses the single-layer UCM (SLUCM) with a static $Q_{F}^{5,6}$ profile (traffic and $A C$ ) giving parallel results to urban warming without $Q_{F}$ emissions (see next section 'Model settings').

\section{Model settings}

Here the Advanced Research WRF model (ver. 3.5.1) ${ }^{4}$ was used with the same model parameters (Supplementary Table 3 ) and physics as previously described. ${ }^{51}$ The specific schemes used are: updated Rapid Radiation Transfer Model (RRTMG) short- and long-wave radiation schemes, ${ }^{56}$ WRF single-moment three-class (WSM3) cloud microphysics scheme, ${ }^{57,58}$ Mellor-Yamada-Janjic atmospheric boundary-layer scheme, ${ }^{59-61}$ Noah land surface model, ${ }^{62}$ and BEP+BEM model. ${ }^{34-36}$ As previously indicated, these models can accurately reproduce the diurnal variation and horizontal distribution of summertime surface air temperature and $E C$ due to $A C$ use. $^{51}$

The model domain (Supplementary Fig. 2a) covers western Japan with $126 x$ and $y$ grids in both d01 and d02 domains (horizontal resolution 5 and $1 \mathrm{~km}$, respectively, and two-way nesting). As the reanalysis captures the summer synoptic-scale features (high-pressure system) around Japan, ${ }^{63}$ a larger coarse grid is not needed. The model top is $50 \mathrm{hPa}$, with 35 vertical sigma levels. The vertical resolution close to the ground (WRF atmospheric first layer height) is nearly $50 \mathrm{~m}$. Therefore, 10 building layers below $50 \mathrm{~m}$ ( $5 \mathrm{~m}$ resolution) in BEP/BEM is used, as in previous studies, ${ }^{42,51}$ due to high model reproducibility for $2 \mathrm{~m}$ air temperature and $E C$ in Osaka with the first layer at $50 \mathrm{~m}$. With a mean building height of about $25 \mathrm{~m}$ in the office area, $50 \mathrm{~m}$ corresponds to the constant flux layer. The innermost domain urban grid classifications are based on the dominant building type, using land use and land cover and topographic data sets from the Geospatial Information Authority of Japan data and Osaka City GIS polygon (building footprint) data, with building use (type), building height and total floor area for each building (Supplementary Fig. 2c, d) grouped into: (i) commercial and business grids (i.e. mainly commercial and office buildings; hereafter C), (ii) residential grids with predominantly fireproof apartments (Rr), and (iii) residential grids with predominately wooden detached dwellings (Rw). The outer and inner domain urban grids outside Osaka City are classified as Rw.

For current climate simulation, initial and boundary conditions are derived from the National Center for Environmental Prediction-National Center for Atmospheric Research (NCEP-NCAR) reanalysis data ${ }^{64}$ and merged satellite and in situ global daily sea surface temperature (MGDSST) data. ${ }^{65}$ For future climate simulations, we also use a modified the NCEP-NCAR and MGDSST as initial and boundary conditions (see details in the next subsection). As previously, ${ }^{3}$ time integration is conducted from 00:00 UTC July 27 to September 1 (i.e. August with 5 days spin-up) for 11 years 2000-2010 to allow climatological discussion of the simulation results. Other studies integrate for only 1 month, several weeks or days (current and future climate), which is insufficient for climatological discussion in general. In Osaka, August is the hottest month, with more clear skies (cf. June, July and September, rainy season) and the highest $E C$ recorded. These model settings are termed the control simulation (case $\mathrm{AC} \rightarrow \mathrm{FB}$ ) (Fig. 1b, red arrow) for all climates, including current and six future climates (see next subsection).

The no- $Q_{F}$, AC simulation (case $A C \neq F B$ ) differs from case $A C \rightarrow F B$ as $Q_{F}, A C=0 \mathrm{~W} \mathrm{~m}^{-2}$ (Fig. $1 \mathrm{~b}$, blue arrow); i.e. the $[A C \neq F B]-[A C \rightarrow F B]$ difference is caused by $Q_{F}, A C$ and it causes the feedback $\left(\delta T_{A C \rightarrow F B}\right)$. Current climate conditions (August 2000-2010) and six future climates are simulated. Here $\delta T_{A C \rightarrow F B}$ is estimated by $\Delta T_{A C \rightarrow F B}-\Delta T_{A C \neq F B}$ (Fig. 1b). In the current climate case, $\delta T_{A C \rightarrow F B}$ is $0{ }^{\circ} \mathrm{C}$ as we assume there is no longterm climate change (decades) (i.e. no increase in forcing temperature and $\Delta T_{\mathrm{AC} \rightarrow \mathrm{FB}}$ and $\Delta T_{\mathrm{AC} \neq \mathrm{FB}}$ are $0^{\circ} \mathrm{C}$ ). Of course, $\delta T_{\mathrm{AC} \rightarrow \mathrm{FB}}$ may not be $0^{\circ} \mathrm{C}$ in the real current climate, but it is difficult to estimate $\delta T_{A C \rightarrow F B}$ from current climate only, and our objectives are to clarify $\delta T_{\mathrm{AC} \rightarrow \mathrm{FB}}$ in relation to future urban climate and how $\delta T_{\mathrm{AC} \rightarrow \mathrm{FB}}$ is changed by climate change (see 'Introduction'). Therefore, here ' $\delta T_{A C \rightarrow F B}$ driven by decades of climate change' is the focus and is estimated by a time slice experiment, including current climate simulation and six future projections. In a similar way, $\delta E C_{A C \rightarrow F B}$ is estimated by $\triangle E C_{A C \rightarrow F B}-\triangle E C_{A C \neq F B}$. To determine $\delta T_{A C \rightarrow F B}$ and $\delta E C_{A C \rightarrow F B}$, it is assumed all conditions (e.g. urban structures, human activities and $\mathrm{AC}$ system technology) remain constant, except for background climate change. Although AC technology will improve, it is important to know the maximum (potential) impact of the feedback driven by climate change on future urban air temperature. A constant COP scenario is used as the RCP8.5, and Shared Socioeconomic Pathway 3 scenario assumes slow technological change in the energy sector. ${ }^{66,67}$

We assume that $\delta T_{A C \neq F B}$ is constant with $\Delta T_{G W}$; i.e. black dashed arrow $\left(\Delta T_{\text {const.QF }}\right)$ parallel to the blue arrow $\left(\Delta T_{\mathrm{AC} \neq \mathrm{FB}}\right)$ in Fig. $1 \mathrm{~b}$. To confirm this, the impact of $Q_{F}$ on surface air temperature (i.e. like $\delta T_{\mathrm{AC} \neq \mathrm{FB}}$ ), on future climate, was conducted with simulations using SLUCM, which has a static $Q_{F}^{5,6}$ (includes traffic and $A C$ ). Urban warming, when $Q_{F}$ in the future was the same as for the current climate ( $\Delta T_{\text {const.QF }}$ : Fig. $1 \mathrm{~b}$, black dashed arrow), paralleled urban warming with a no- $Q_{\mathrm{F}}$ emitted case, like $\Delta T_{\mathrm{AC} \neq \mathrm{FB} \text {, }}$ although different urban parameterisation was used. A reason why we used SLUCM (not BEP/BEM) to confirm black dashed arrow ( $\Delta T_{\text {const.oF)'s }}$ gradient $\left(\Delta T_{\text {const.QF }} / \Delta T_{\mathrm{GW}}\right)$ (and then compared with that of blue arrow $\left(\Delta T_{\mathrm{AC} \neq \mathrm{FB}}\right)$ by $\left.\mathrm{BEP} / \mathrm{BEM}\right)$ is that it is quite difficult to calculate the black dashed arrow by the BEP/BEM, because $Q_{F}, A c$ at every time step $(6 s)$ in future climates has to be completely same as that of current climate. To confirm the black arrow's gradient by SLUCM is technically much easier and essentially same as that by the BEP/BEM.

\section{Climate projections}

Six future climates, with background temperature increases (global warming: $\Delta T_{\mathrm{GW}}:+0.5,+1.0,+1.5,+2.0,+2.5$, and $+3.0^{\circ} \mathrm{C}$ ) relative to the current climate, are simulated. These are based on the ensemble mean results from four GCMs used in the Climate Model Intercomparison Project (CMIP5) $^{68}$ : CCSM4, ${ }^{69}$ CESM1 (CAM5), ${ }^{70}$ GFDL-CM3 $^{71}$, and INM-CM4. ${ }^{72}$ However, the ensemble mean of only three GCMs (CCSM4, CESM1 and GFDL-CM3) is used when $\Delta T_{G W}>+3.0^{\circ} \mathrm{C}$, as INM-CM4 does not reach $+3.0^{\circ} \mathrm{C}$ at 2100 . The simulations considered the highest IPCC GHG emissions scenario (RCP8.5) (Fig. 4). CESM1 (CAM5) and CCSM4 have good model climate performance index scores ${ }^{73}$ and summertime synoptic pressure patterns around Japan perform better than other GCMs. GFDLCM3 and INM-CM4 are selected to cover minimum to maximum uncertainties in GCM projections. By using several GCMs, the uncertainties in the GCM projections (horizontal colour bars, Fig. 4) are incorporated in the RCM. A similar GCMs selection method for future urban climate projection was used by Adachi et al. ${ }^{9}$

For future projection experiments, climate difference components between current and future are estimated by the four individual GCMs. For example, for $\Delta T_{\mathrm{GW}}=+0.5^{\circ} \mathrm{C}$, it was identified that the August mean surface air temperature difference, averaged spatially around Japan, became nearly $+0.5^{\circ} \mathrm{C}$ for each GCM. The other climate variables (e.g. geopotential height, horizontal wind and sea surface temperature) are extracted for each GCM for the identified years, and an ensemble mean is calculated for all variables. For $\Delta T_{G W}=+0.5^{\circ} \mathrm{C}$, the ensemble mean surface air temperature difference component is $+0.4725^{\circ} \mathrm{C}$ (Supplementary Fig. 3) (i.e. nearly $+0.5^{\circ} \mathrm{C}$ ). The actual ensemble mean surface air temperature differences for $\Delta T_{\mathrm{GW}}=+0.5,+1.0,+1.5,+2.0,+2.5$ and $+3.0^{\circ} \mathrm{C}$ are $+0.4725,+0.9550,+1.4750,+1.9650,+2.4450$ and $+2.8825^{\circ} \mathrm{C}$, respectively (Supplementary Fig. 3). For the six $\Delta T_{\mathrm{GW}}$ cases, the climate difference for each variable (i.e. wind components, geopotential height and temperature) are added to the NCEP-NCAR and MGDSST data (Supplementary Fig. 3), therefore changing the atmospheric variables such as long-wave radiation. Note, future climate relative humidity is assumed to be the same as the current climate. ${ }^{74-78}$

The PGW method ${ }^{7,8}$ was used to create regional climate projections $^{3,10,11,21,79-81}$ and has been previously verified. ${ }^{80,82,83}$ For example, Kawase et al. ${ }^{82}$ projected East Asia's 1960 s climate by the PGW method using 1990s reanalysis data and PGW increment, calculated by the climate difference between the 1990s and 1960s. They compared the $1960 \mathrm{~s}$ projection results with a hindcast simulation for the same period using reanalysis data. They showed that the 1960s projection could reproduce some decadal changes in the rainfall shown within the hindcast simulation, thus indicating that the PGW method could reproduce actual energy 
balance change using reanalysis, as precipitation is calculated in response to the atmospheric energy balance.

Yoshikane et al..$^{83}$ compared PGW and direct downscaling from GCM for East Asian future climate projections and found no significant differences in temperature and precipitation (i.e. atmospheric energy balances were similar). Snowfall ${ }^{79,81,84}$ research, a process strongly influenced by atmospheric energy balance near the surface, and torrential rain ${ }^{85}$ studies, caused by atmospheric buoyancy near the surface, have also successfully used PGW methods. Therefore, the PGW method is reasonable for use in future projection research. An advantage of using the PGW method is a reduction in GCM climate bias as the method uses modified objective analysis/re-analysis data rather than GCM output. ${ }^{10} \mathrm{~A}$ disadvantage is that perturbations in meteorological variables are not considered. ${ }^{86}$ As Adachi et $a l^{87}$ show, the perturbation component is equally important as the climatology component for summer precipitation, hence the PGW method is inappropriate for this. However, the perturbations do not affect nearsurface air temperatures change (current to future climates) in western Japan, including Osaka during summer. ${ }^{87}$ Thus the difference in climatology projected by a GCM has a larger influence than the difference in perturbation on the downscaled temperature change and its variability in the climate projections. ${ }^{87}$ Hence, as the main contributor to the temperatures change was climate change (PGW) component, their results indicate that PGW method is appropriate for our purpose. As we focus on August, a dry period in Japan, surface air temperature is little impacted by precipitation. The PGW method is used as it enabled the study to focus on internal physical (feedback) processes in the RCM and to remove bias from individual GCMs. It also allows for direct comparison with previous PGW studies that report projected urban temperature uncertainties with selections of RCM, GHG emission scenarios and urban planning scenarios (see Table 1 and main text).

\section{Normalised feedback impact}

Three urban land uses are selected for analysis (Supplementary Fig. 2d): commercial and office buildings, fireproof apartments, and wooden detached dwellings. These types of areas were evaluated for surface air temperature and EC model performance. ${ }^{48}$

To address the question (1), a normalised $\delta T_{\mathrm{AC} \rightarrow \mathrm{FB}}$ (feedback impact) per future climate is determined:

Normalised $\delta T_{\mathrm{AC} \rightarrow \mathrm{FB}}=\frac{\left(\Delta T_{\mathrm{AC} \rightarrow \mathrm{FB}}-\Delta T_{\mathrm{AC} \neq \mathrm{FB}}\right)}{\Delta T_{\mathrm{GW}}}$

where $\Delta T_{\mathrm{AC} \rightarrow \mathrm{FB}}$ and $\Delta T_{\mathrm{AC} \neq \mathrm{FB}}$ are urban warming calculated by the $\mathrm{AC} \rightarrow$ $F B$ and $A C \neq F B$, respectively, as explained in Fig. 1.

All times referred to are LT. Japan does not use summertime.

\section{DATA AVAILABILITY}

The downscaling data by the WRF are deposited in local storage at AIST. This is available from the corresponding author upon reasonable request. The source code of the WRF and future projection results by four global climate models (CCSM4, CESM1 (CAM5), GFDL-CM3 and INM-CM4) that support findings of this study are available from websites: http://www2.mmm.ucar.edu/wrf/users/ and https://esgfnode.IInl.gov/projects/esgf-IInl/, respectively. The observational data used in this study are available from the website of the Japan Meteorological Agency: https:// www.jma.go.jp/jma/index.html.

Received: 16 April 2019; Accepted: 3 October 2019; Published online: 25 October 2019

\section{REFERENCES}

1. Population Division, Department of Economic and Social Affairs, United Nations. World Urbanization Prospects: The 2014 Revision, Highlights (ST/ESA/SER.A/352) (United Nations, 2014).

2. Georgescu, M., Morefield, P. E., Bierwagen, B. G. \& Weaver, C. P. Urban adaptation can roll back warming of emerging megapolitan regions. Proc. Natl. Acad. Sci. 111, 2909-2914 (2014).

3. Kusaka, H., Hara, M. \& Takane, Y. Urban climate projection by the WRF model at 3-km grid increment: dynamical downscaling and predicting heat stress in the 2070's August for Tokyo, Osaka, and Nagoya. J. Meteorol. Soc. Jpn. 90B, 47-64 (2012).
4. Skamarock, W. C. et al. A description of the Advanced Research WRF version 3. NCAR Technical Note NCAR/TN-4751STR, $113 \mathrm{pp}$. [Available online at http://www. mmm.ucar.edu/wrf/users/docs/arw_v3. pdf] (NCAR, 2008).

5. Kusaka, H., Kondo, H., Kikegawa, Y. \& Kimura, F. A simple single-layer urban canopy model for atmospheric models: comparison with multi-layer and slab models. Bound. Layer. Meteorol. 101, 329-358 (2001).

6. Kusaka, H. \& Kimura, F. Coupling a single-layer urban canopy model with a simple atmospheric model: Impact on urban heat island simulation for an idealized case. J. Meteorol. Soc. Jpn. 82, 67-80 (2004).

7. Kimura, F. \& Kitoh, A. Downscaling by pseudo global warming method. The Final Report of the ICCAP, Research Institute for Humanity and Nature, Kyoto, Japan (ICCAP, 2007).

8. Sato, T., Kimura, F. \& Kitoh, A. Projection of global warming onto regional precipitation over Mongolia using a regional climate model. J. Hydrol. 333, 144-154 (2007).

9. Adachi, S. A., Kimura, F., Kusaka, H., Inoue, T. \& Ueda, H. Comparison of the impact of global climate changes and urbanization on summertime future climate in the Tokyo metropolitan area. J. Appl. Meteorol. Climatol. 51, 1441-1454 (2012).

10. Kusaka, H., Suzuki-Parker, A., Aoyagi, T., Adachi, S. A. \& Yamagata, Y. Assessment of RCM and urban scenarios uncertainties in the climate projections for August in the 2050s in Tokyo. Clim. Change 137, 427-438 (2016).

11. Doan, Q. V. \& Kusaka, H. Projections of urban climate in the 2050 s in a fastgrowing city in Southeast Asia: the greater Ho Chi Minh City metropolitan area, Vietnam. Int. J. Climatol. 38, 4155-4171 (2018).

12. Hamdi, R., Van de Vyver, H., De Troch, R. \& Termonia, P. Assessment of three dynamical urban climate downscaling methods: Brussels's future urban heat island under an A1B emission scenario. Int. J. Climatol. 34, 978-999 (2014).

13. Grossman-Clarke, S., Schubert, S. \& Fenner, D. Urban effects on summertime air temperature in Germany under climate change. Int. J. Climatol. 37, 905-917 (2016).

14. Conlon, K., Monaghan, A., Hayden, M. \& Wilhelmi, O. Potential impacts of future warming and land use changes on intra-urban heat exposure in Houston, Texas. PLOS ONE 11, e0148890 (2016).

15. Krayenhoff, E. S., Moustaoui, M., Broadbent, A. M., Gupta, V. \& Georgescu, M. Diurnal interaction between urban expansion, climate change and adaptation in US cities. Nat. Clim. Change 8, 1097-1103 (2018).

16. Argüeso, D., Evans, J. P., Fita, L. \& Bormann, K. J. Temperature response to future urbanization and climate change. Clim. Dyn. 42, 2183-2199 (2013).

17. Kusaka, $\mathrm{H}$. et al. Numerical simulation of urban heat island effect by the WRF model with 4-km grid increment: An inter-comparison study between the urban canopy model and slab model. J. Meteorol. Soc. Jpn. 90B, 33-45 (2012).

18. Ashie, Y., Vu Thanh, C. \& Asaeda, T. Building canopy model for the analysis of urban climate. J. Wind Eng. Ind. Aerodyn. 81, 237-248 (1999).

19. Kikegawa, Y., Genchi, Y., Yoshikado, Y. \& Kondo, H. Development of a numerical simulation system for comprehensive assessments of urban warming countermeasures including their impacts upon the urban buildings' energy-demands. Appl. Energy 76, 449-466 (2003).

20. Sailor, D. J. A review of methods for estimating anthropogenic heat and moisture emissions in the urban environment. Int. J. Climatol. 31, 189-199 (2011).

21. $\mathrm{Li}, \mathrm{C}$. et al. Interaction between urban microclimate and electric air-conditioning energy consumption during high temperature season. Appl. Energy 117, 149-156 (2014).

22. Salamanca, F., Georgescu, M., Mahalov, A., Moustaoui, M. \& Wang, M. Anthropogenic heating of the urban environment due to air conditioning. J. Geophys. Res. Atmos. 119, 5949-5965 (2014).

23. Ohashi, Y. et al. Impact of seasonal variations in weekday electricity use on air temperature observed in Osaka, Japan. Q. J. R. Meteorol. Soc. 142, 971-982 (2016).

24. Hassid, S. et al. The effect of the Athens heat island on air conditioning load. Energy Build. 32, 131-41 (2000).

25. Kolokotroni, M., Giannitsaris, I. \& Watkins, R. The effect of the London urban heat island on building summer cooling demand and night ventilation strategies. Sol. Energy 80, 383-392 (2006).

26. Ihara, T., Genchi, Y., Sato, T., Yamaguchi, K. \& Endo, Y. City-block-scale sensitivity of electricity consumption to air temperature and air humidity in business districts of Tokyo, Japan. Appl. Energy 33, 1634-1645 (2008).

27. Lindberg, F., Grimmond, C. S. B., Yogeswaran, N., Kotthaus, S. \& Allen, L. Impact of city changes and weather on anthropogenic heat flux in Europe 1995-2015. Urban Clim. 4, 1-15 (2013).

28. Kimura, F. \& Takahashi, S. The effects of land-use and anthropogenic heating on the surface temperature in the Tokyo metropolitan area: a numerical experiment. Atmos. Environ. 25B, 155-164 (1991).

29. Ichinose, T., Shimodozono, K. \& Hanaki, K. Impact of anthropogenic heat on urban climate in Tokyo. Atmos. Environ. 33, 3897-3909 (1999). 
30. Ohashi, Y. et al. Influence of air-conditioning waste heat on air temperature in Tokyo office areas during summer: numerical experiments using an urban canopy model coupled with a building energy model. J. Appl. Meteorol. Climatol. 46, 66-81 (2007).

31. de Munck, C. et al. How much can air conditioning increase air temperatures for a city like Paris, France? Int. J. Climatol. 33, 210-227 (2013).

32. Wang, Y. et al. Effects of anthropogenic heat due to air-conditioning systems on an extreme high temperature event in Hong Kong. Environ. Res. Lett. 13, 034015 (2018).

33. $\mathrm{Xu}, \mathrm{X}$. et al. Using WRF-urban to assess summertime air conditioning electric loads and their impacts on urban weather in Beijing. J. Geophys. Res. Atmos. 123, 2475-2490 (2018)

34. Martilli, A., Clappier, A. \& Rotach, M. W. An urban surface exchange parameterization for mesoscale models. Bound. Layer. Meteorol. 104, 261-304 (2002).

35. Salamanca, F., Krpo, A., Martilli, A. \& Clappier, A. A new building energy model coupled with an urban canopy parameterization for urban climate simulations part I. formulation, verification, and sensitivity analysis of the model. Theor. Appl. Climatol. 99, 331-344 (2010)

36. Salamanca, F. \& Martilli, A. A new building energy model coupled with an urban canopy parameterization for urban climate simulations - part II. Validation with one dimension off-line simulations. Theor. Appl. Climatol. 99, 345-356 (2010).

37. IPCC. in Climate Change 2014: Impacts, Adaptation, and Vulnerability. Part A: Global and Sectoral Aspects. Contribution of Working Group II to the Fifth Assessment Report of the Intergovernmental Panel on Climate Change (eds Field, C. B. et al.) 1-32 (Cambridge University Press, Cambridge, 2014).

38. Japan Refrigeration and Air Conditioning Industry Association. World air conditioner demand by region https://www.jraia.or.jp/english/World_AC_Demand.pdf (2017).

39. United Nations Framework Convention on Climate Change. Paris Agreement: FCCC/CP/2015/L.9/Rev.1. Retrieved from https://unfccc.int/documentation/ documents/advanced_search/items/6911.php?priref=600008831 (2015).

40. Takane, Y. et al. Future projection of electricity demand and thermal comfort for August in Nagoya city by WRF-CM-BEM (in Japanese with English abstract). J. Environ. Eng. AlJ 80, 973-983 (2015).

41. Kondo, H. et al. Development of a multi-layer urban canopy model for the analysis of energy consumption in a big city: Structure of the urban canopy model and its basic performance. Bound. Layer. Meteorol. 116, 395-421 (2005).

42. Kikegawa, Y., Tanaka, A., Ohashi, Y., Ihara, T. \& Shigeta, Y. Observed and simulated sensitivities of summertime urban surface air temperatures to anthropogenic heat in downtown areas of two Japanese Major Cities, Tokyo and Osaka. Theor. Appl. Climatol. 117, 175-193 (2014).

43. Tewari, M., Salamanca, F., Martilli, A., Treinish, L. \& Mahalov, A. Impacts of projected urban expansion and global warming on cooling energy demand over a semiarid region. Atmos. Sci. Lett. 18, 419-426 (2017).

44. Takane, Y., Ohashi, Y., Kusaka, H., Shigeta, Y. \& Kikegawa, Y. Effects of synoptic-scale wind under the typical summer pressure pattern on the mesoscale high-temperature events in the Osaka and Kyoto urban areas by the WRF model. J. Appl. Meteorol. Climatol. 52, 1764-1778 (2013).

45. Zhao, L., Lee, X., Smith, R. B. \& Oleson, K. Strong contribution of local background climate to urban heat island. Nature 511, 216 (2014).

46. Takane, Y., Kusaka, H. \& Hara, M. Urban climate projection in the 2070's August for the three major metropolitan areas under the IPCC SRES A2 emission scenario: dynamical downscaling by the WRF-UCM (in Japanese with English abstract). J. Heat. Isl. Inst. Int. 7, 18-26 (2012).

47. Saito, K. et al. Nonhydrostatic atmospheric models and operational development at JMA. J. Meteorol. Soc. Jpn. 85B, 271-304 (2007).

48. Fujibe, F. Urban warming in Japanese cities and its relation to climate change monitoring. Int. J. Climatol. 31, 162-173 (2011).

49. Adachi, S. A. et al. Moderation of summertime heat island phenomena via modification of the urban form in the Tokyo metropolitan area. J. Appl. Meteorol. Climatol. 53, 1886-1900 (2014).

50. Japan Meteorological Agency. Extreme weather during summer of 2013 in Japan: summary of analysis by abnormal weather investigative commission (in Japanese) https://www.jma.go.jp/jma/press/1309/02d/extreme20130902.pdf (2013).

51. Takane, Y. et al. A climatological validation of urban air temperature and electricity demand simulated by a regional climate model coupled with an urban canopy model and a building energy model in an Asian mega city. Int. J. Climatol. 37, 1035-1052 (2017)

52. Shimoda, Y., Takahara, Y. \& Mizuno, M. Estimation and impact assessment of energy flow in urban area. Proc. 5th Int. Conf. EcoBalance S5-28, 727-730 (2002).

53. Chow, W. T. L. et al. A multi-method and multi-scale approach for estimation citywide anthropogenic heat fluxes. Atmos. Environ. 99, 64-76 (2014).
54. Sailor, D. J., Georgescu, M., Milne, J. M. \& Hart, M. A. Development of a national anthropogenic heating database with an extrapolation for international cities. Atmos. Environ. 118, 7-18 (2015).

55. Ministry of Economy, Trade and Industry, Japan (Daiwa Institute of Research Ltd). Report of market development project for developing countries on 2014 (in Japanese). http://www.meti.go.jp/meti_lib/report/2015fy/000341.pdf (2015).

56. lacono, M. J. et al. Radiative forcing by long - lived greenhouse gases: calculations with the AER radiative transfer models. J. Geophys. Res. 113, D13103 (2008).

57. Dudhia, J. Numerical study of convection observed during the winter monsoon experiment using a mesoscale two-dimensional model. J. Atmos. Sci. 46, 3077-3107 (1989)

58. Hong, S.-Y., Dudhia, J. \& Chen, S.-H. A revised approach to ice microphysical processes for the bulk parameterization of clouds and precipitation. Mon. Weather Rev. 132, 103-120 (2004).

59. Mellor, G. C. \& Yamada, T. Development of a turbulence closure model for geophysical fluid problems. Rev. Geophys. Space Phys. 20, 851-875 (1982).

60. Janjic, Z. The Step - Mountain Eta Coordinate Model: further developments of the convection, viscous sublayer, and turbulence closure schemes. Mon. Weather Rev. 122, 927-945 (1994).

61. Janjic, Z. Nonsingular implementation of the Mellor-Yamada level 2.5 scheme in the NCEP Meso model. NCEP Off. Note 436, 61 (2002).

62. Chen, F. \& Dudhia, J. Coupling an advanced land-surface/hydrology model with the Penn State/NCAR MM5 modeling system. Part I: Model description and implementation. Mon. Weather Rev. 129, 569-585 (2001).

63. Takane, Y., Kusaka, H. \& Kondo, H. Climatological study on mesoscale extreme high temperature events in the island of the Tokyo Metropolitan Area, Japan, during the past 22 years. Int. J. Climatol. 34, 3926-3938 (2014).

64. Kalnay, E. et al. The NCEP/NCAR 40-Year Reanalysis Project. Bull. Am. Meteorol. Soc. 77, 437-471 (1996).

65. Kurihara, Y., Sakurai, T. \& Kuragano, T. Global daily sea surface temperature analysis using data from satellite microwave radiometer, satellite infrared radiometer and in-situ observation (in Japanese). Weather Serv. Bull. 73, S1-S18 (2006).

66. Riahi, K. et al. RCP 8.5 - a scenario of comparatively high greenhouse gas emissions. Clim. Change 109, 33-57 (2011).

67. O'Neill, B. C. et al. A new scenario framework for climate change research: the concept of shared socioeconomic pathways. Clim. Change 122, 387-400 (2014).

68. Taylor, K. E., Stouffer, R. J. \& Meehl, G. A. An overview of CMIP5 and the experiment design. Bull. Am. Meteorol. Soc. 93, 485-498 (2012).

69. Gent, P. R. et al. The community climate system model version 4. J. Clim. 24, 4973-4991 (2011).

70. Meehl, G. A. et al. Climate change projections in CESM1(CAM5) compared to CCSM4. J. Clim. 26, 6287-6308 (2013).

71. Donner, L. J. et al. The dynamical core, physical parameterizations, and basic simulation characteristics of the atmospheric component of the GFDL global coupled model CM3. J. Clim. 24, 3484-3518 (2011).

72. Volodin, E. M., Diansky, N. A. \& Gusev, A. V. Simulating present-day climate with the INMCM4.0 coupled model of the atmospheric and oceanic general circulations. Izv. Atmos. Ocean. Phys. 46, 414-431 (2010).

73. Gleckler, P. J., Taylor, K. E. \& Doutriaux, C. Performance metrics for climate models. J. Geophys. Res. 113, D06104 (2008).

74. Wright, J. S., Sobel, A. \& Galewsky, J. Diagnosis of zonal mean relative humidity ghanges in a warmer climate. J. Clim. 23, 4556-4569 (2010).

75. Sherwood, S. C. et al. Relative humidity changes in a warmer climate. J. Geophys. Res. 115, D09104 (2010)

76. Kamae, Y. \& Watanabe, M. On the robustness of tropospheric adjustment in CMIP5 models. Geophys. Res. Lett. 39, L23808 (2012).

77. Kamae, Y., Watanabe, M., Ogura, T., Yoshimori, M. \& Shiogama, H. Rapid adjustments of cloud and hydrological cycle to increase $\mathrm{CO}_{2}$ : a review. Curr. Clim. Change Rep. 1, 103-113 (2015).

78. Byrne, M. P. \& O'Gorman, P. A. Understanding decreases in land relative humidity with global warming: Conceptual model and GCM simulations. J. Clim. 29, 9045-9061 (2016).

79. Hara, M., Yoshikane, T., Kawase, H. \& Kimura, F. Estimation of the impact of global warming on snow depth in Japan by the pseudo-global warming method. Hydrol. Res. Lett. 2, 61-64 (2008).

80. Kawase, H. et al. Intermodel variability of future changes in the Baiu rainband estimated by the pseudo global warming downscaling method. J. Geophys. Res. 114, D24110 (2009).

81. Rasmussen, R. et al. High-resolution coupled climate runoff simulations of seasonal snowfall over Colorado: a process study of current and warmer climate. J. Clim. 24, 3015-3048 (2011).

82. Kawase, $\mathrm{H}$. et al. Downscaling of the climatic change in the Mei-yu rainband in East Asia by a pseudo climate simulation method. SOLA 4, 73-76 (2008) 
83. Yoshikane, T., Kimura, F., Kawase, H. \& Nozawa, T. Verification of the performance of the Pseudo-Global-Warming method for future climate changes during June in East Asia. SOLA 8, 133-136 (2012).

84. Gutmann, E. D. et al. A comparison of statistical and dynamical downscaling of winter precipitation over complex terrain. J. Clim. 25, 262-281 (2012).

85. Manda, A. et al. Impacts of a warming marginal sea on torrential rainfall organized under the Asian summer monsoon. Sci. Rep. 4, 5741 (2014).

86. Adachi, S. A. et al. Contribution of changes in climatology and perturbation and the resulting nonlinearity to regional climate change. Nat. Commun. 8, 2224 (2017).

87. Adachi, S. A. et al. An evaluation method for uncertainties in regional climate projections. Atmos. Sci. Lett. 20, e877 (2019).

\section{ACKNOWLEDGEMENTS}

This study is supported by JSPS Overseas Research Fellowships and JSPS KAKENHI Grant-in-Aid for Scientific Research (B) Number 16H04441. We thank EPSRC LoHCool (EP/N009797/1). We also thank Dr. Sachiho A. Adachi of RIKEN Advanced Institute for Computational Sciences for helpful advice associated with the selection of GCMs, and Mr. Toshiharu Nagatomo of National Institute of Advanced Industrial Science and Technology (AIST) who helped with some data analyses. The numerical simulations are performed under the 'Interdisciplinary Computational Science Program' in the Center for Computational Sciences, University of Tsukuba. The free software package Generic Mapping Tools (GMT) is used to draw the figures.

\section{AUTHOR CONTRIBUTIONS}

Y.T., Y.K. and M.H. conceived the study and designed the analyses. S.G. provided an important idea. M.H. prepared the forcing data for regional climate simulations, and Y.T. conducted the simulations and analysis using this forcing data. Y.T. wrote the original manuscript and S.G., Y.K. and M.H. provided comments, feedback and revisions to the manuscript.

\section{COMPETING INTERESTS}

The authors declare no competing interests.

\section{ADDITIONAL INFORMATION}

Supplementary information is available for this paper at https://doi.org/10.1038/ s41612-019-0096-2.

Correspondence and requests for materials should be addressed to Y.T.

Reprints and permission information is available at http://www.nature.com/ reprints

Publisher's note Springer Nature remains neutral with regard to jurisdictional claims in published maps and institutional affiliations.

Open Access This article is licensed under a Creative Commons Attribution 4.0 International License, which permits use, sharing, adaptation, distribution and reproduction in any medium or format, as long as you give appropriate credit to the original author(s) and the source, provide a link to the Creative Commons license, and indicate if changes were made. The images or other third party material in this article are included in the article's Creative Commons license, unless indicated otherwise in a credit line to the material. If material is not included in the article's Creative Commons license and your intended use is not permitted by statutory regulation or exceeds the permitted use, you will need to obtain permission directly from the copyright holder. To view a copy of this license, visit http://creativecommons. org/licenses/by/4.0/.

(c) The Author(s) 2019 